community issue, was proposed the creation of an adolescents nursing consultation. This idea gave birth to the 'Light House Project'.

Four areas of focus were explored and objectives outlined. The general objective was to promote the community adolescent's health in matters of mental health, sexuality, interpersonal relationships and healthy lifestyle, with each of the areas having its own objectives. The purpose was being able to demonstrate, quantify and evaluate the fulfilment of the objectives. Instruments or indicators of structure, process and result were created. Those instruments were built according to instructions made available by the 'Ordem dos Enfermeiros' in Nursing Care Continuous Quality Improvement Project Organization Script and also according to International Classification for Nursing Practice. As result of this work, and during the first half of 2016, a new service was to be opened specifically for adolescents, comprising a multidisciplinary team, with a nursing consultation and dedicated instruments that will allow the continuous improvement of the nursing care provided by this service.

\title{
OC23 - Expert mentoring: a path to leadership
}

\author{
Carol Hall (United Kingdom) ${ }^{1}$; Paula Dawson (United Kingdom)i; \\ Laura Holliday (United Kingdom)1
}

\section{${ }^{1}$ University of Nottingham School of Health Sciences}

Theme: Nursing education, management and leadership.

Keywords: Contemporary nursing challenge, expert mentor, leadership, problem-solving, teamwork.

Leadership knowledge and skills development may be understood in terms of problem-solving, solution construction and social judgement needed to solve organizational problems (Mumford, Zaccaro et al 2000). Capacity and courage to lead as a nurse for children and young people will impact upon all elements of health care, from direct care to service commissioning (RCN 2014).

Final year undergraduate MSc child nursing students worked in action learning sets, facilitated by nationally recognised expert mentors, and were required to identify, explore and tackle a contemporary challenge in nursing practice, considering strategic, managerial and operational issues.

Student groups presented their findings, analyses, recommendations and reflections upon team and individual development at a shared conference event.

Our presentation will discuss perceived immediate and longer-term effects of participation in this innovative educational initiative of current students and alumni on career aspirations and trajectories, networking skills, knowledge and confidence to lead and challenge in professional practice. 